\title{
Fabrication and Evaluation of Proper Building Thermal Insulation Materials
}

\author{
${ }^{1}$ Nooraldeen Saleh Khider, ${ }^{2}$ Anwar Mohammed Mostafa, ${ }^{3}$ Arab Ghazi Azeez, ${ }^{4}$ Saeed Saleh Khider \\ ${ }^{1,3}$ Assistant Lecturer, Mechanical Engineering Department, College of Engineering, University of Mosul, Iraq \\ ${ }^{2}$ Lecturer, Mechanical Engineering Department, College of Engineering, University of Mosul, Iraq \\ ${ }^{4}$ Private Sector Engineer, Iraq \\ Emails: ${ }^{1}$ nooralelln2017@uomosul.edu.iq, ${ }^{2}$ anwar1964@uomosul.edu.iq, ${ }^{3}$ arabghaziazeez@uomosul.edu.iq, \\ ${ }^{4}$ saied241111@gmail.com
}

Abstract - In this research, an empirical work study to investigate the thermal insulation properties of a mixture of some selected wastes of different composition, represented by (polyethylene, Styropor, active carbon, and rubber) for a purpose to use in a building isolation. These wastes are mixed with cement using a different volumetric percentage ratio as (10 to 30$)$ percentage, with $5 \%$ increase for each test trial. A Lee's Disc, apparatus is used to measure the thermal conductivity for each constructed mold. Through which the thermal conductivity of the proportions added with cement is determined. Knowing this fact, the effect of these additives on the effectiveness and quality as an insulating mixture is analyzed and compared with each other to get finally the best possible mixture ratio.

From the preliminary examinations, it is found that all the mixing materials prepared with their volume ratios mention above, have a good thermal insulation property as its thermal conductivity rate does not exceed the range of $(0.300835)$. This value is located below the average in the heat-conducting materials scale, especially for thermal insulators used for concrete prepared for work construction.

Tests are conducted on the prepared samples to get in mind the effect of these insulating materials with their indicated percentages on the cement insulating behavior, leading finally to the choose of the best ones. The obtained results and readings of these samples are compared with the results taken from the cement without any additives. All experimental results proved that the behavior of the thermal conductivity coefficient with their additive indicated are versible relation with the percentage step up of the volume ratio. In addition, (active carbon mixture) is chosen as the best mixing insulating material, specifically at the mixing ratio of $(30 \%)$ ranged.

Keywords: Lee's Disc, Thermal Conductivity, Active Carbon, Rubber, Polyethylene, Styropor, Cement.

\begin{tabular}{|l|l|l|}
\hline \multicolumn{3}{|c|}{ NOMENCLATURES } \\
\hline Symbols & Term & Unit \\
\hline $\mathrm{A}$ & Area & $\mathrm{m}^{2}$ \\
\hline $\mathrm{c}$ & Specific heat & $\mathrm{J} / \mathrm{kg} . \mathrm{k}$ \\
\hline $\mathrm{D}$ & Diameter & $\mathrm{M}$ \\
\hline $\mathrm{k}$ & Thermal Conductivity & $\mathrm{W} / \mathrm{m} . \mathrm{k}$ \\
\hline $\mathrm{m}$ & Mass & $\mathrm{Kg}$ \\
\hline $\mathrm{r}$ & Radius & $\mathrm{m}$ \\
\hline $\mathrm{T}$ & Temperature & $\mathrm{K},{ }^{0} \mathrm{C}$ \\
\hline $\mathrm{t}$ & Time & $\mathrm{sec}$ \\
\hline $\mathrm{x}$ & Thickness & $\mathrm{m}$ \\
\hline
\end{tabular}

\section{INTRODUCTION}

The importance of thermal insulation has emerged intensely with the emergence of the energy crisis in the seventies of the last century as a result of the high oil prices and the resort of consuming countries, especially industrial ones. So, within the framework of the optimal use of resources, the search for alternatives and means of aimed to reduce and rationalize consumption being the main goal. Thermal insulation was one of the most prominent of these means because it's positive economic impact on the consumer and the state.

The most important factor affecting in heat transfer through building, walls and ceilings is the thermal conductivity of its constituent materials. Therefore, the use of poor thermal conductivity building materials reduces heat transfer rates through them. The use of thermal insulators is one of the main means that can contribute to this, so it is necessary to resort to an extensive and necessary study of the thermal properties, especially thermal conductivity [1]. The present study is considered complementary to those endeavors by calculating the thermal conductivity of some insulating materials mixed in volumetric ratio with cement.

A review to the previous researches and studies published in this field, it turns out that there are many experimental and theoretical studies that have been completed by researchers. Begging with the researcher Russel, 1935[2] conducted a experimental study on a porous insulator, and during his study 
ISSN (online): 2581-3048

Volume 6, Issue 2, pp 28-34, February-2022

https://doi.org/10.47001/IRJIET/2022.602006

he was able to arrive at an analytical method for heat transfer through the porous insulator by calculating the thermal conductivity of the porous material present through it, and his study also included the effect of the size and shape of the air gaps of the porous. Luikov, 1968[3] and others conducted an experimental and theoretical study of the thermal conductivity of granular and cellular materials. They also studied the effect of surface roughness at the contact point, porosity, and the shape of the structural of the porous material. There is a great agreement between experimental and theoretical results. Battacharyya, 1980[4] also conducted a experimental study where he proved that the thermal conductivity of the insulator is the rate of thermal conductivity of the fibers when they are perpendicular or parallel to the direction of heat transfer. Shirtliffe, 1980 [5] conducted many studies and researches on heat transfer in fibrous insulating materials, he reached several mathematical models for the relationship of thermal conductivity with the volumetric ratio of each of the fibrous material and the gas gaps inside it. Hammoud 1983 [6], he studied the possibility of using rice husks as a thermal insulator, who in turn used two-sample hot plate apparatus to measure the thermal conductivity. By change thickness, average temperature, density, and percentage of the binder in the samples, he concluded that the thermal conductivity is affected little by temperature and thickness, and concluded also that it changes directly with temperature and inversely with thickness, up to a certain limit of (172 mm).It also proved that the bulk density and the ratio of the bonding material are more influential than the temperature and thickness, and the thermal conductivity is directly proportional to both. The obtained experimental results matched the mathematical equations in previous research which represent mathematical models of heat transfer in fibrous insulating materials. Adam 1997 [7] also studied the effect of the percentage of reeds in cement, the density of the panels, the size of the reeds, and the amount of moisture on the effective thermal conductivity coefficient according to the sound transmission. He used two samples with dimensions $(29 \times 29 \mathrm{~cm})$ laboratory-made. One of the samples, a hot plate apparatus used to measure its thermal conductivity parameter, after which the results obtained is compared with the previous one, with an error rate of $10 \%$. Finally, Nawaf 1997[8], used the thermal conductivity measurement apparatus at different temperatures by adopting the unstable method for measurement. He studied the effect of adding cellulosic materials with weight ratios ranging between (0.0-10.0) \% to the cement on the coefficient of thermal conductivity, tensile and compression resistance. He proved that the value of these thermal and mechanical properties decreases by increasing the weight ratios of the additives. He also recommended the use of sawdust as a best insulating material due to the improvement in the mechanical and thermal properties.

\section{EXPERIMENTAL PREPARATION}

The Present study included several stages, first step, identifying the parts of the apparatus used and its method of work. Then the defined (Lee's Disc) diameter is checked in order to get proper measurement of temperature for each sample. On the other hand, to get more accuracy and better operation of the device used, a calibration is carried out by conducting a practical experiment to evaluate the thermal conductivity of the window glass more than once and comparing the results obtained with a reference source. Second step, the preparation procedure of the cement mortar mixed with the locally waste materials is taken place, by set them in a pre-prepared measuring mold, of $(10.4 \mathrm{~cm}$ diameter $)$ and ( $1 \mathrm{~cm}$ thickness) made of polyvinyl chloride (PVC). The mold is confined in a sandwiched shape between two glass plates in order to obtain a uniform thickness as well as a flat surface of the manufactured samples.

(Lee's Disc) device as mention above is used here as an experimental thermal device for measuring poor thermal conductivity materials. It consists of a nickel-plated disc coated with brass, a steam chamber, bearing, two thermometers, and samples of measure as shown in figure (1).

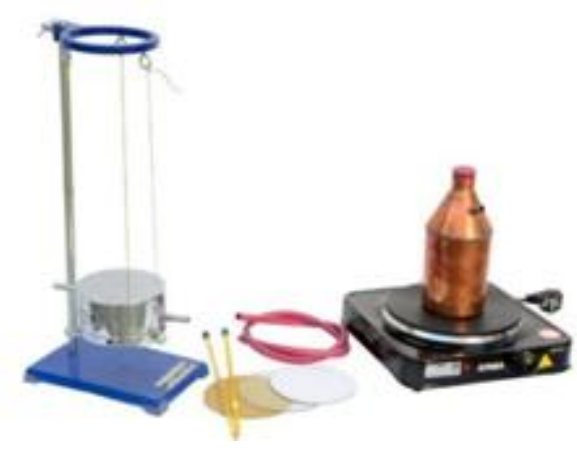

Figure 1: Lee's Disc) for measuring the thermal conductivity of poorly conductive materials [9]

For measurement, Lee disk device prepared to estimate the heat transfer coefficient by conduction at the steady state situation within a heat source supply. The model used to calculate its thermal conductivity is placed between the two discs of the device in such way that the heat current will transfer in one direction. Fourier's law is adopted as it is considered the theoretical basis for measuring thermal conductivity in the steady state, and it depends on one principle of heat namely conduction heat.[10]

$$
Q=-K A d T / d X------------------------(1)
$$

To find the thermal conductivity, the amount of heat lost from the braze disc is calculated using the following mathematical relationship [10]. 


$$
Q=m \times c \times(d T / d t)
$$

\section{Parts of the apparatus used}

A Lee's Disc made of nickel-plated braze, drilled with an orifice hole groove fit in with glass thermometer for reading disc temperature $\left(\mathrm{T}_{2}\right)$. It also contains three drilled holes where annular screws are fixed to hang the assembly together as in the arrangement shown in figure (3). Steam chamber for possessing steam contains two other holes for entry and exit of the steam and in its lower part there is a disc similar to the main disc with a longitudinal cavity hole extending inside, Through which a thermometer for measuring temperature passes through which recorded the upper part of the disc $\left(\mathrm{T}_{1}\right)$. Other constituent, steam generator, boiler, flexible tubes to transfer steam from the heater to the steam chamber, stand to carry the device parts, sample for testing its thermal conductivity.

\section{Composite Samples Preparation}

The proces of sampleing begin witha pouring sample mold ( $10.4 \mathrm{~cm}$ diameter) and (1cm thickness) used for mold construction, mixing the cement mortar with each of the choosen materials (cork, rubber, active carbon and polyethylene) with their volumetric ratios ranging from $(10 \%$, to $30 \%$ ) $5 \%$ increase, the mold is placed between two pieces of glass in order to get a better surfaces levelness and good confinment of the mixed morter. Thus 20 models areseting up using this manner, as it shown in figure (2).

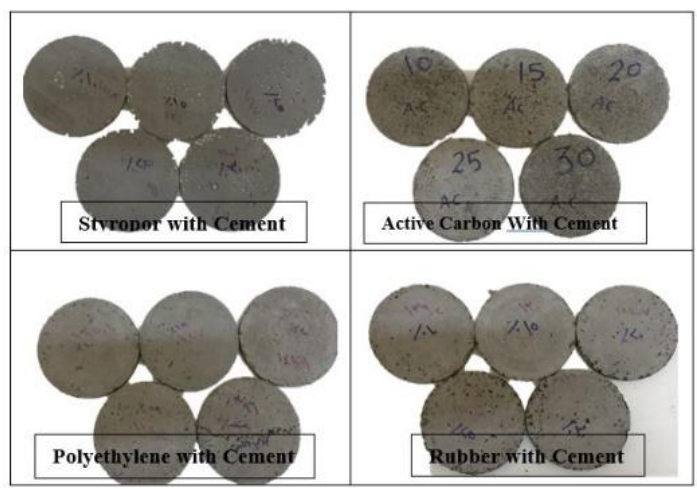

Figure 2: Shows the models with cement mortar

\section{Working Procedure}

First measuring the mass of the disc and its specific heat (nickel-plated braze disc). Followed by measuring diameter and thickness of the sample whose thermal conductivity coefficient is to be calculated. The sample is setting up between the two discs A \& B as noted in figure (3) and then the whole assembly is suspended from the bearing ring. Being in mind the whole set-up is maintained in a horizontal flat position as shown in figure (3).

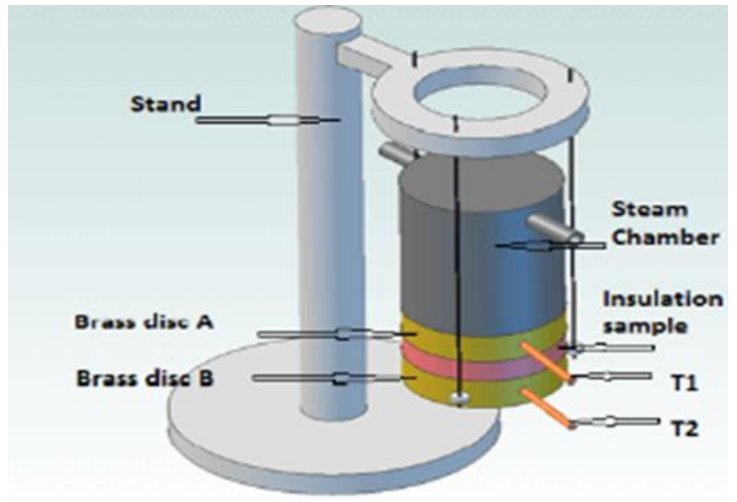

Figure 3: Shows the Lee disc, the holder and the thermometers in the presence of the model [11]

The water in the evaporation vessel is heated by an electric heater until the water begins to boil and turns into steam. The resulting steam is transferred by a tube to the steam chamber, which in turn works as the main source heat needed for testing. Both thermostats are installed in the existing designated slot, upper and lower discs. Heating process and monitoring the temperature of the thermometers is going on till the temperature of the upper and lower dials is stable. After reaching the stable state (stability of the thermometers reading), A recording of the two thermometers is taken for the upper and lower dials represented by $\left(\mathrm{T}_{1}, \mathrm{~T}_{2}\right)$.Then the model raises from the two discs as shown in figure (4).And finally ending the heating stage by first cutting the provide steam running to the steam chamber room, followed by removing the chamber above the lower disc. So, the examine sample is left on the lower disc and start recording the rate of heat loss (by natural cooling) by following the decrease in temperature of the disc with time using a stopwatch.

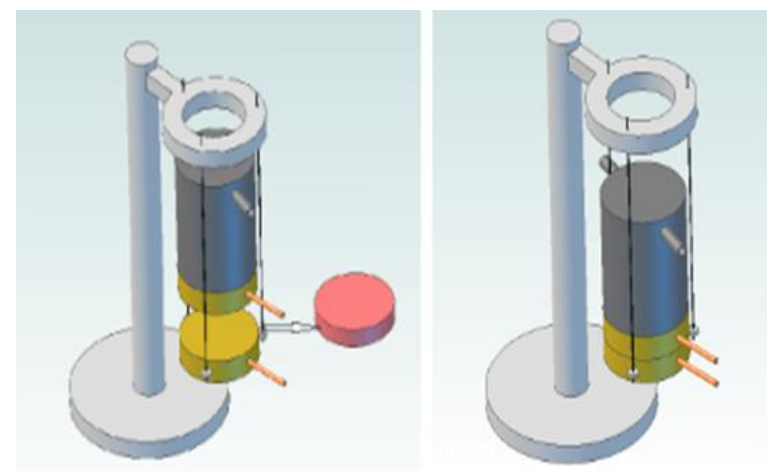

Figure 4: Lift the model upon reaching the Stability condition [11]

Temperature reduction of the metal disc is noted with time (and here be sure that the disc loses heat gradually under the same conditions) with the sample remaining above the disc, recording the temperature of the disc within half a minute until (7 to 10) degrees above and below the stability temperature $\left(\mathrm{T}_{2}\right)$. Then these readings are converted to a graphic curve 
ISSN (online): 2581-3048

Volume 6, Issue 2, pp 28-34, February-2022

https://doi.org/10.47001/IRJIET/2022.602006

showing the relationship between temperature and time as shown in figure (5). The point of stability is located on the plotting curve (cooling curve) and a line drawn straightly through this point as tangent to the curve. The slope at this point represents the temperature rate of reduction with time.

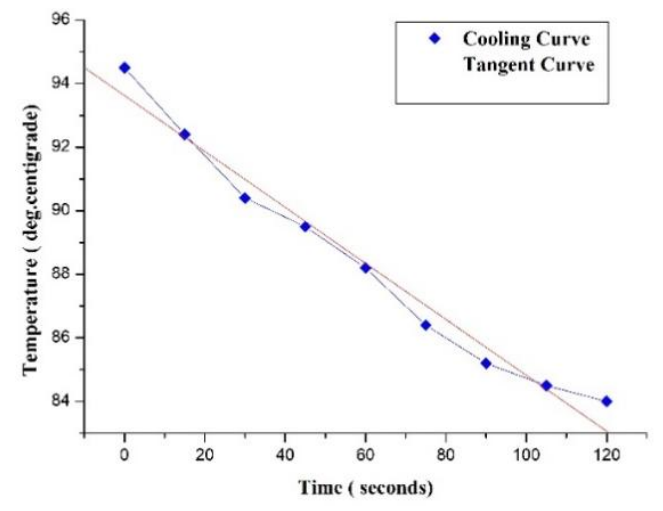

Figure 5: Cooling curve

\section{THERMAL CONDUCTIVITY MEASUREMENT}

The value of $\mathrm{K}$ is calculated using the following law [12]

$$
K=\{m \times c \times x \times(d T / d t) /(A \times \Delta T)\}
$$

Where $: d T / d t=$ slope,$\Delta T=\left(T_{2}-T_{1}\right)$.

\section{SAMPLE OF CALCULATION}

A sample of glass was used to conduct the calibration in order to ensure the correctness of the used method, as the value of the thermal conductivity of the glass as found in scientific sources is equal to one. A table No.1 showing the specifications of the glass used in the test.

\begin{tabular}{|l|l|l|l|}
\hline \multicolumn{4}{|c|}{ Table no. 1 specifications of glass disc used } \\
\hline Term & Symbols & Value & Unit \\
\hline Thickness of specimen & $\mathrm{X}$ & 0.02 & $\mathrm{~cm}$ \\
\hline Diameter of specimen & $\mathrm{d}$ & 10.4 & $\mathrm{~cm}$ \\
\hline Mass of the disc & $\mathrm{m}$ & 0.986 & $\mathrm{~kg}$ \\
\hline specific heat & $\mathrm{C}$ & 0.380 & $\mathrm{~kJ} / \mathrm{kg} . \mathrm{k}$ \\
\hline
\end{tabular}

Applying equation no. (2). from the cooling curve of the glass, the slope $d T / d t$ is found.

$$
\begin{gathered}
d T / d t=(92.1-89.3) /(40-15)=0.122 C^{o} / \mathrm{sec} \\
\begin{aligned}
A=1 / 4 \pi D^{2}= & (\pi / 4)(10.4 \times 10-2)^{2} \\
& =8.4948665 \times 10^{-2} \mathrm{~m}^{2}
\end{aligned}
\end{gathered}
$$

Where: $T_{1}=99 C^{o} \& T_{2}=90.6 C^{o}$

$\Delta T=\left(T_{2}-T_{1}\right)=99-90.6=8.4 C^{o}$

By applying the following equation (3), we get the value of thermal conductivity $(\mathrm{K})$ :

$$
\begin{gathered}
K=\frac{0.986 \times 0.380 \times 0.112 \times 2 \times 10-3}{8.4 \times 8.4948665 \times 10-3} \\
=1.091 \mathrm{~W} / \mathrm{m} . \mathrm{k}
\end{gathered}
$$

The experiment was repeated with the same previous steps on the models used in the study, and the results were as follows:

\begin{tabular}{|l|l|l|l|l|l|l|}
\hline \multicolumn{6}{|c|}{ Table No. 2. Values of thermal conductivity for composites poor } \\
thermal conductivity material with cement \\
\hline $\begin{array}{l}\text { Particulate } \\
\text { Content } \\
\text { (Vol.\%) }\end{array}$ & $0 \%$ & $10 \%$ & $15 \%$ & $20 \%$ & $25 \%$ & $30 \%$ \\
\hline cement & 0.50 & & & & & \\
& 785 & & & & & \\
\hline $\begin{array}{l}\text { Poly } \\
\text { ethylene }\end{array}$ & & 0.4384 & 0.37 & 0.3027 & 0.27 & 0.2565 \\
\hline Styropor & & 0.4037 & 0.39 & 0.3782 & 0.35 & 0.3111 \\
& & 6 & 643 & 5 & 04 & 5 \\
\hline Rabber & & 0.4638 & 0.41 & 0.3909 & 0.36 & 0.3506 \\
& & 3 & 76 & 4 & 644 & 4 \\
\hline $\begin{array}{l}\text { Active } \\
\text { Carbon }\end{array}$ & & 0.4008 & 0.32 & 0.2749 & 0.20 & 0.1378 \\
\hline
\end{tabular}

\section{RESULTS AND DISCUSSION}

The thermal conductivity is evaluated experimentally using different compounds of (Polyethylene, Styropor, Rubber, and Active carbon) respectively with cement mortar are shown in figures $(6,7,8,9)$. Each figure shows the mixing effect of the additive materials to the cement mortar on the thermal conductivity behavior. It shows all that there is a benefit in its thermal conductivity reduction as the percentage for each cement compounds increases, i.e., improvement in its ability to insulate. This result may be attributed to the air spaces created in during the preparation of the compound mold. Furthermore, the actual thermal conductivity of each individual additive named as (Polyethylene, Styropor, Rubber, and Active carbon) are less than the thermal conductivity of the cement mortar without any additives. Therefore, increasing their percentage decreases the thermal conductivity of the compound. On the other hand, grain construction and shape play a great role to get these interests especially as an isolated material in construction work. They assumed to be spherical while the actual ones are irregular in shape and randomly distributed into the mold space, they in fact dispersed in the cement mortar almost randomly lead to this expected result. As the materials added in different volumetric ratios ranging $(10,15,20,25,30) \%$ respectively. So adding Polyethylene with their ratio of percentages shows a drop in its thermal conductivity as $(13.67,26.78,40.383,45.15) \%$ in a constituent to each additive ratio above. While the percentage of decrease when adding Styropor yield to (20.496, $21.939,25.52,31.0,38.73)$ respectively, as shown in table (3). Whereas its percentage when adding Rubber as follows (8.668, 17.77, 23.020, 27.845, 30.956) respectively. Finally, when the Active carbon added, the decrease in thermal 
ISSN (online): 2581-3048

conductivity achieves $(21.070,35.951,45.8639,59.234$, 72.858), respectively as indicated in table (4).Looking closely to all the figures which represent the twenty test results of the specimens prepared with their additive volume ratio indicated a reversible relation between the thermal conductivity and their volume ratio of the isolated materials. The models which contain $10 \%$ volume ratio have higher thermal conductivity with respect to other ratios. Then it decreases as the volume ratio increases in the cement mortar, till it reach the least one at the volume ratio of $30 \%$. The results revel that the active carbon has the least value of $(0.13784 \mathrm{~J} / \mathrm{kg} . \mathrm{k})$ thermal conductivity at the volume ratio of $30 \%$ compared to all the models tested. Whereas the rubber discover the biggest value of $(0.46383 \mathrm{~J} / \mathrm{kg}$. $\mathrm{k})$ thermal conductivity at the volume ratio of $10 \%$ with the cement mortar. The rest of specimen will drop in between the two extreme values.

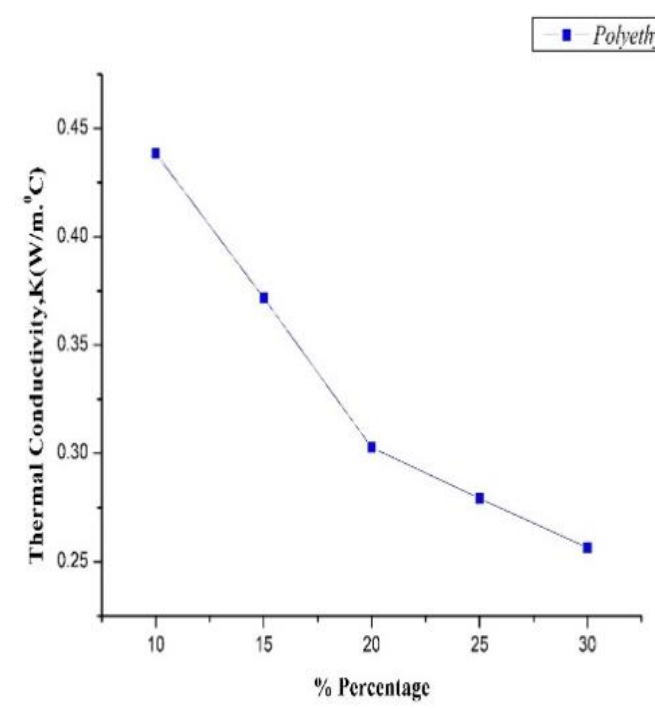

Figure 6: Shows the relationship between the percentages of addition of polyethylene with cement mortar

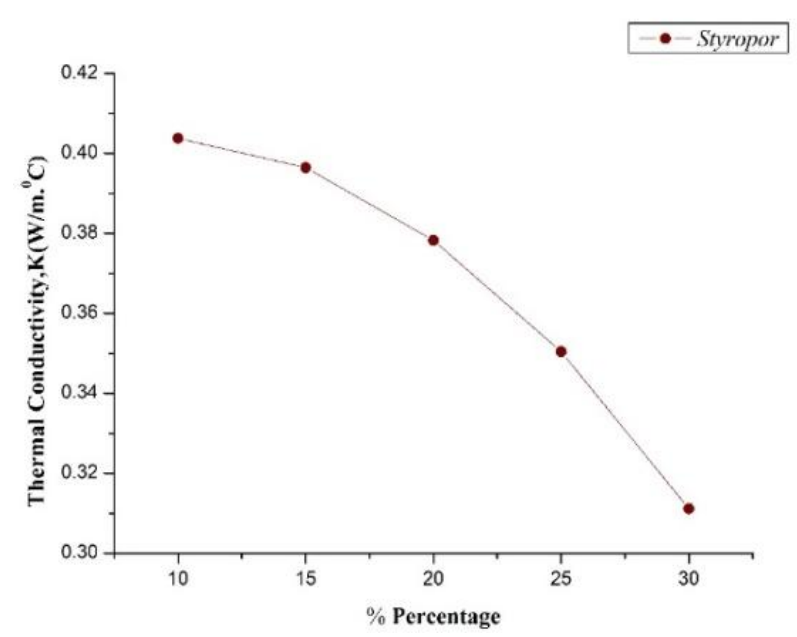

Figure 7: Shows the relationship between the percentage of addition of cork material with cement mortar

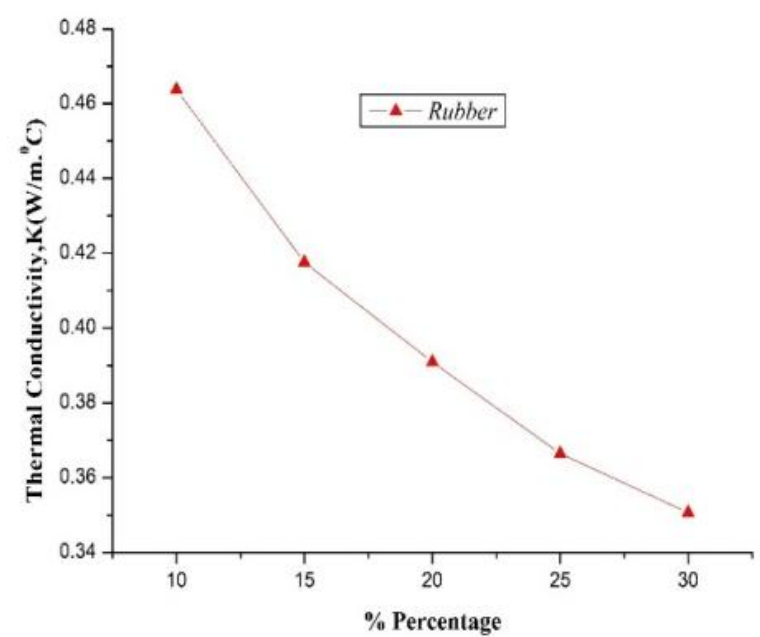

Figure 8: Shows the relationship between the percentage of addition of rubber and cement mortar

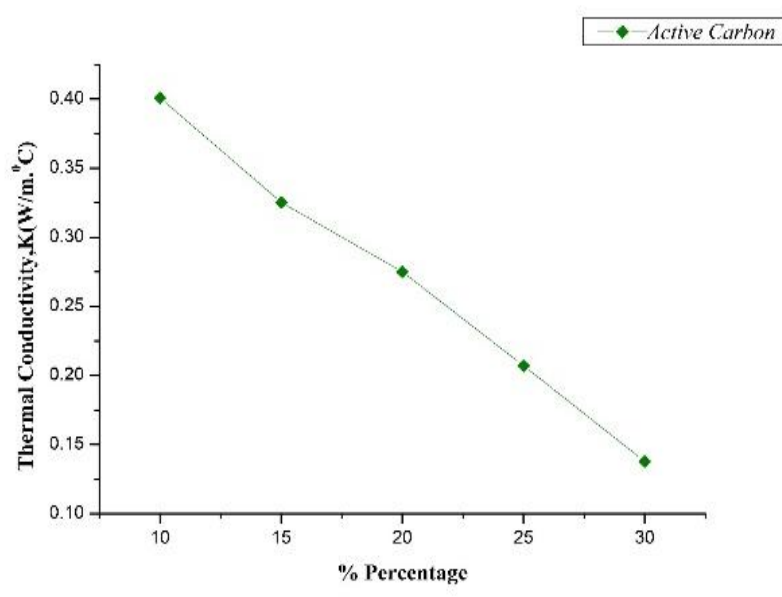

Figure 9: Shows the relationship between the percentage of addition of active carbon with cement mortar

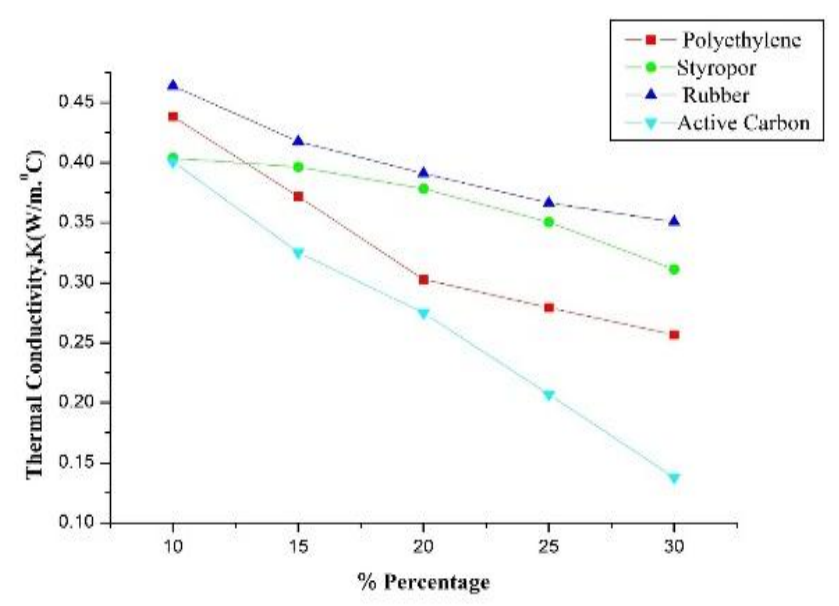

Figure 10: Shows the comparison of the thermal conductivity of all types of additives with cement 
Table no. 3: Values of thermal conductivity for composites poor thermal conductivity material with cement

\begin{tabular}{|c|c|c|c|c|c|c|}
\hline $30 \%$ & $25 \%$ & $20 \%$ & $15 \%$ & $10 \%$ & $0 \%$ & Particulate Content (Vol.\%) \\
\hline & & & & & 0.50785 & Cement \\
\hline 0.256555 & 0.279241 & 0.30276 & 0.3718 & 0.43842 & & \begin{tabular}{c} 
Poly ethylene \\
\hline 49.483
\end{tabular} \\
& 45.015 & 40.383 & 26.789 & 13.67 & & \\
\hline 0.31115 & 0.3504 & 0.37820 & 0.39643 & 0.40376 & & $\begin{array}{c}\text { \%reduction of thermal Conductivity with respect } \\
\text { to neat Cement }\end{array}$ \\
\hline 38.73 & 31.0 & 25.52 & 21.939 & 20.496 & & Styropor \\
& & & & & \\
\hline
\end{tabular}

Table no. 4: Values of thermal conductivity for composites poor thermal conductivity material with cement

\begin{tabular}{|c|c|c|c|c|c|c|}
\hline $30 \%$ & $25 \%$ & $20 \%$ & $15 \%$ & $10 \%$ & $0 \%$ & Particulate Content (Vol.\%) \\
\hline & & & & & 0.50785 & Cement \\
\hline 0.35064 & 0.36644 & 0.39094 & 0.4176 & 0.46383 & & Rabber \\
\hline 30.956 & 27.845 & 23.020 & 17.77 & 8.668 & & $\begin{array}{c}\text { \%reduction of thermal Conductivity with respect } \\
\text { to neat Cement }\end{array}$ \\
\hline 0.13784 & 0.20703 & 0.27493 & 0.32527 & 0.400841 & & Active Carbon \\
\hline 72.858 & 59.234 & 45.8639 & 35.951 & 21.070 & & $\begin{array}{c}\text { \%reduction of thermal Conductivity with respect } \\
\text { to neat Cement }\end{array}$ \\
\hline
\end{tabular}

\section{CONCLUSION}

The following conclusions can be extraction from the above analysis:

- Environmental wastes such as rubber, cork, polyethylene, and active carbon can be profitably used in the preparation of composite materials.

- Environmental waste compounds mention above which have lower heat conduction stabilize the use of these additive as an isolator in construction work.

- It is found that the thermal conductivity of composite materials made from environmental wastes such as rubber, cork, polyethylene and active carbon decreases with the increase of its content in the composition.

- Because of the improved insulating ability of these compounds, it can be used in applications such as insulation panels for walls, secondary roofs of structures, as well as in floor slabs for structures, etc.

- The most suitable mixture to use for all facilities is the one that contains activated carbon at a mixing rate of $(30 \%)$.

\section{REFERENCES}

[1] Faris Musa Raffa, "The effect of adding Thermal insulating grains to concrete on thermal conductivity and compressive strength". 2009. Journal of technical colleges, university of Kirkuk.

[2] Russell, H.w., "Principle of heat flow in porous insulation,"Journal of America ceramic society", vol.18. No.1, (1935), pp,1.5.
[3] Luikov, A.v,Shashkov,. A.G., Vasliev, L.L., and Fairman, \%E., "Thermal conductivity of porous system", Int. J. heat and mass transfer, vol.11, 1968. pp.117-140.

[4] Battacharya, R.K, "Heat transfer model for fibrous insulation, "Thermal insulation performance", ASTM STP718, MeElroy, D.L., and Tye, R.P., Eds., ASTM 1980, pp.272-286.

[5] Shirtiffe,c.j. "Effect of thickness on the thermal properties of thick specimens of low-density thermal insulation thermal insulation performance", ASTM, PP.36-50-1980.

[6] Hammoud Abdullah Hammoud, "Using rice husk as heat insulator" A thesis submitted for degree of master in the University of Technology Basra, 1983.

[7] Shmuel Khoshaba Adam, "A practical and theoretical study of the thermal and acoustic properties of cement reed panels", Ph.D. thesis in Mechanical Engineering, University of Mosul (1997).

[8] Nawaf Bao Al-Hadidi, "The effect of cellulosic materials on the thermal and mechanical properties of Portland cement", Master's thesis in Physics, University of Mosul, 1997.

[9] Engg-BE Btech 1st Year Lees Disc Charlton apparatus Thermal Conductivity of a Bad Conductor Vernier Calipersabron https://abronexports.com/EnggBEBtech1stYearLeesDiscCharltonapparatusThermalCo nductivityofaBadConductorVernierCalipersabron.html

[10] Ashrae hand book fundamentals, 1981.

[11] Charles H. Lee's. J.D. Chorlton, LIV. "On a simple apparatus for determing the thermal conductivity of 
ISSN (online): 2581-3048

cements and other substances used in the arts .Vol.41, ISSUE 253-1896.

[12] M. Alam, S. Rahman, P.K. Halder, A. Raquib, M. Hasan, 'Lee's and Charlton's Method for Investigation of Thermal Conductivity of Insulating Materials", IOSR Journal of Mechanical and Civil Engineering (IOSR-JMCE) ISSN: 2278-1684 Volume 3, Issue 1, (Sep-Oct. 2012), PP 53-60.

\section{AUTHOR'S BIOGRAPHIES}

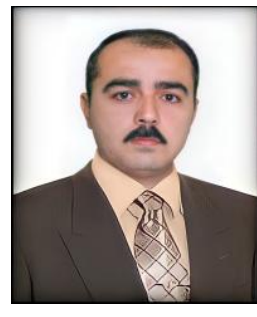

Nooraldeen Saleh khider AL-Eniz was born in Talafer, Mosul north of Iraq, is an assistant lecturer at department of Mechanical engineering, College of engineering, University of Mosul. I did my master degree in Fluids and heating / Internal Combustion engine at Mosul University, Iraq 2018. I did my Bachelor degree in Mechanical engineering/ Energy and Heating system at University of Mosul, Iraq 2000. Mr. Khider is in heat transfer and internal combustion engine, Mr. Khider is also interesting in combined power plants and Air pollutant, Mr. Khider is a faculty Member at University of Mosul college of engineering /Mechanical engineering department since 2006. Mr. Khider is a faculty Member of Iraq engineering Association since 2000. Mr. Khdier has research published in "Theoretical study of spark ignition engine performance using a blend of gasoline and Oxygenated Fuels "Effect of combustion duration on the performance and emission of four stroke spark ignition engine using

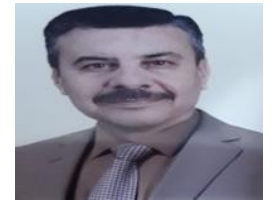

https://doi.org/10.47001/IRJIET/2022.602006

gasoline -biofuel blend". And "A Review of a mechanical vapour compression refrigeration system: Environment and performance challenge".

Anwar Mohammed was born in Mosul. I graduated from the city university (Mosul) to receive the B.Sc. specialized in general mechanic, Then, M.Sc. degrees and later the Ph.D. degree from the same university (Mosul). The M.Sc. degree taken in the field of refrigerating and air conditioning, while the Ph.D. being in thermal power field at the dates of 1989 , 1993, 2009 respectively. Currently, he is a lecturer in mechanical engineering at Mosul university teaching the advance mathematics and numerical analysis. Although he is already an academic member of mechanical engineering faculty in Mosul university. Recently my interest is focused in heat transfer of source of heat with different shapes in an empty enclosure.

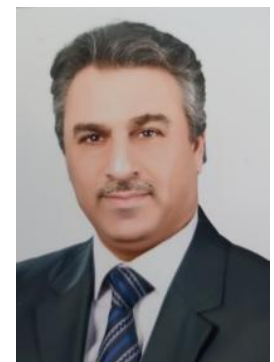

Arab Ghazi Azeez was born in Mousl city. He received the B.SC., and the M.Sc., degrees from University of Technology in Baghdad. All in mechanical Engineering. In 1988, 2005, respectively. Currently, he is an assistant teacher in Mousl University. He is also a faculty member in Mousl University. $\mathrm{He}$ is teacher of engineering mechanics, control systems, vibrations, and fluid mechanics.

\section{Citation of this Article:}

Nooraldeen Saleh Khider, Anwar Mohammed Mostafa, Arab Ghazi Azeez, Saeed Saleh Khider, "Fabrication and Evaluation of Proper Building Thermal Insulation Materials" Published in International Research Journal of Innovations in Engineering and Technology - IRJIET, Volume 6, Issue 2, pp 28-34, February 2022 . Article DOI https://doi.org/10.47001/IRJIET/2022.602006 